\title{
REMOTE SENSING MONITORING AND ANALYSIS OF AGRICULTURAL DROUGHT IN SPRING CONSIDERING IRRIGATION AREA: A CASE STUDY OF DONGLEI IRRIGATION DISTRICT (PHASE II)
}

\author{
Hongjie Liu ${ }^{1}$, Wenlong Song ${ }^{*}$, Yuanyuan Duan ${ }^{1}$, Tao Sun ${ }^{1}$, Huanxin $\mathrm{Li}^{3}$, Linjing Tian ${ }^{2}$, Yizhu Lu ${ }^{1}$, Yun Liu ${ }^{1}$, Mengyi Li $^{2}$ \\ ${ }^{1}$ China Research Center on Flood \& Drought Disaster Reduction of the Ministry of Water Resources, Beijing, P.R.China \\ ${ }^{2}$ Capital Normal University, Beijing 100038, P.R.China. \\ ${ }^{3}$ Weinan Donglei Yellowing Project Management Center, P.R.China
}

Commission III, WG III /10

KEY WORDS: drought, irrigated area, percentage of precipitation anomaly, AVI, surface temperature, MODIS

\begin{abstract}
:
As one of the common natural disasters, drought is extremely destructive to agriculture. Drought has risen in recent years, so how to effectively monitor drought has become the focus of attention of relevant government departments. When drought occurs, irrigation measures will be taken in the irrigation district for drought resistance and disaster reduction. At this time, drought monitoring based on meteorological data and remote sensing index has certain limitations. Based on the surface temperature data of MODIS, this paper extracted the irrigation area information in the irrigated district, compared the drought monitoring results of irrigated area with those based on precipitation anomaly percentage and vegetation anomaly index, and analysed the importance of agricultural drought monitoring based on remote sensing of irrigated area. This paper considers that it is necessary to consider the distribution of the irrigated area when conducting drought monitoring in the irrigation district, it can improve the accuracy of agricultural monitoring, and it can provide the basis for government and agriculture and other related departments to manage water resources and formulate drought-resistance policies.
\end{abstract}

\section{INTRODUCTION}

As one of the common natural disasters in the world, drought is more destructive to agriculture than other natural disasters (Huan Liu et al., 2012; Zhongyan Huang et al., 2013; Limin Wang et al., 2018; Youxin Huang et al., 2015; Yang Song et al., 2016). Drought events of different intensity, different time and different scope have been experienced all over the world. The impact of drought on agriculture has become more and more serious in recent years, resulting in large-scale reduction of crop yields and huge economic losses (Ezzine et al., 2013). Therefore, effective agricultural drought monitoring and response have become the focus of government and public attention. Accurate agricultural drought monitoring can provide a basis for local governments and agriculture-related departments to manage water resources and formulate droughtresistant policies.

Drought monitoring using indices derived from remote sensing data has become an important method for due to its low cost and short period (Gumma, 2011; Wardlow et al., 2008; Xiong et al., 2017; Ouzemou et al., 2015). Among these indices include Anomaly Vegetation Index (AVI) (Weiying Chen et al.,1994; Ming Yan et al.,2010), Temperature Vegetation Drought Index (TVDI)(Patel et al, 2009; Chunsheng Yao et al., 2004; Shuhua Qi et al.,2003), and Conditional Vegetation Index (VCI)(Kogan et al., 1990). The remote sensing vegetation index monitoring method is very advantageous for large-scale drought monitoring, but it does not consider the underlying surface information and cannot reflect the changes of the underlying surface. In addition, drought monitoring methods based on meteorological data are also commonly used, such as the percentage of precipitation anomaly (Henry, 1906; Jie Wei et al., 2003), Palmer Drought Index (PDSI) (Palmer, 1965; Jie Wei et al., 2003), and Standardized Precipitation Index (SPI) (Mckee et al., 1993; Mlenga Daniel et al., 2019) et al.. Drought monitoring based on site data can more accurately reflect meteorological drought, but meteorological drought does not necessarily cause agricultural drought, so there are certain limitations to the monitoring of agricultural drought. However, there are generally complete irrigation facilities in the irrigation district, especially in arid-semi-arid areas. The state has invested a lot of funds to build irrigation facilities to ensure that irrigation is carried out during important growth periods of crops and to ensure food production. Therefore, when drought occurs in the irrigation district, agricultural drought will not occur in the irrigated district. Therefore, monitoring the drought in the irrigation district considering the irrigation area can improve the accuracy of agricultural drought monitoring (Wenlong Song et al., 2019).

Based on MODIS products and meteorological data, this paper obtains the drought monitoring results based on the percentage of precipitation anomalies and the drought monitoring results based on the anomalous vegetation index. The ground surface temperature is used to obtain the irrigated area of the underlying surface, and the rationality of the drought monitoring results of the comprehensive irrigated area is analysed. It is believed that the monitoring of agricultural drought in the irrigated district can improve the monitoring accuracy.

\section{STUDY AREA AND DATA SOURCE}

\subsection{Study area}

In this study, the Donglei Irrigation District (Phase II) in Shaanxi, China was selected as the study area (Figure 1), located at $109^{\circ} 10^{\prime} \sim 110^{\circ} 10^{\prime}$ east longitude and $34^{\circ} 41^{\prime} \sim$

\footnotetext{
* Corresponding author: songwl@iwhr.com
} 
$35^{\circ}$ latitude. The study area is located in the Weibei dry plateau, facing the Yellow River in the east. And the study area has a temperate continental monsoon climate, with warm and dry spring, heavy rain in summer, and severe cold and dry in winter. The average annual rainfall is $519 \sim 552 \mathrm{~mm}$, and the drought years are only $360 \sim 390 \mathrm{~mm}$. The spatial and temporal distribution of precipitation is very uneven. More than $50 \%$ of the rainfall is concentrated from July to September. Therefore, it is known as "the nine droughts in ten years". Weinan City's Donglei Irrigation District (Phase || ) contains 7 irrigation subsystems with a designed irrigation area of 1.265 million mu $(1 \mathrm{mu}=666.67$ square meters $)$.

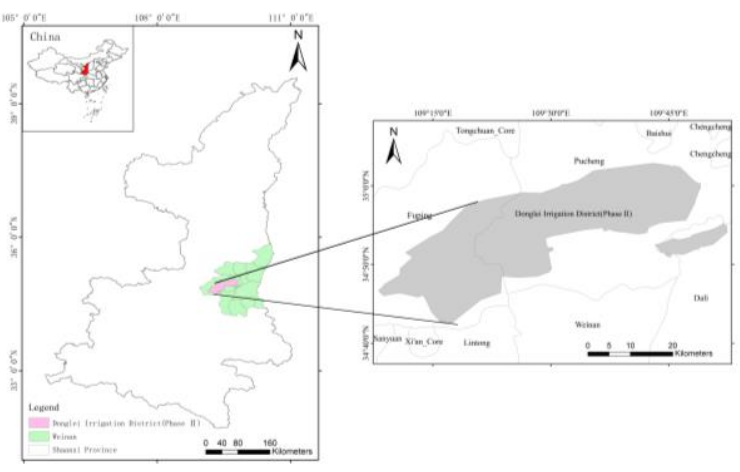

Figure 1. Study area

\subsection{Data source}

The remote sensing data uses MODIS data products. MODIS carries two satellites, Terra and Aqua, with 36 mediumresolution levels ( 0.25 to $1 \mathrm{um})$ of the spectral band. The Earth's surface is observed every 1-2 days to obtain land and ocean temperatures, primary productivity, land surface coverage, clouds, Aerosol, fire, etc. Among them, the resolution of MODIS 1-2 band is $250 \mathrm{~m}$, the resolution of $3-7$ band is $500 \mathrm{~m}$, and the resolution of other bands is $1000 \mathrm{~m}$. This study uses MODIS surface temperature products, Normalized Difference Vegetation Index (NDVI) products, and precipitation data from China Meteorological Data Network. Due to the frequent drought in the study area in March, the March data of the study area was selected for research.

The meteorological data uses the precipitation data in the "China Surface Climate Data Daily Value Data Set (V3.0)" of China Meteorological Data Network. The data set contains daily data of 699 benchmarks, weather stations, temperature, precipitation, evaporation, relative humidity, wind direction and wind speed, sunshine hours, and $0 \mathrm{~cm}$ ground temperature elements of China's 699 base stations and weather stations since January 1951. Data is updated monthly. This paper selects the data from 6 sites around the study area from 2009 to 2018 for processing, and the selected sites are shown in Figure 2, and the numbers in the figure represent the measuring station number.

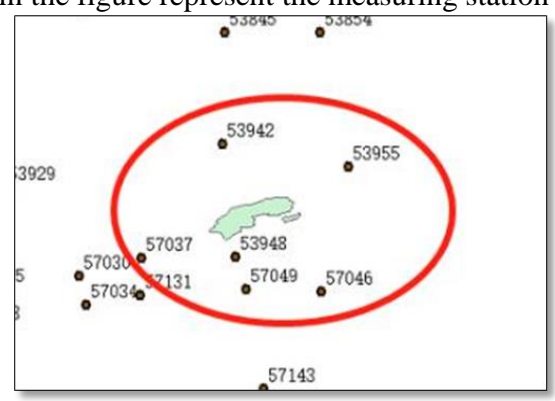

Figure 2. Site selection map

\section{DROUGHT MONITORING METHODS}

This section introduces two methods of using rainfall anomaly percentage and anomaly vegetation index to obtain the drought monitoring method in the study area, and using MODIS surface temperature products to obtain the irrigation area monitoring method in the study area.

\subsection{Drought monitoring method based on percentage of precipitation anomalies}

3.1.1 Method principle: The precipitation anomaly (PA) is both a meteorological drought indicator and an agricultural drought indicator (Mei Ding et al., 2017; Jie Wei et al., 2003). It reflects the deviation of the precipitation from the average state during the same period. Its calculation formula is:

$$
P A=\frac{p-\bar{p}}{\bar{p}} \times 100 \%
$$

where $\quad p=$ precipitation in a certain period

$-\mathrm{p}=$ average precipitation in this period

The PA judges the drought grade. According to the "Meteorological Drought Grade" (GB / T 20481-2017), the grade standard on the monthly scale is shown in Table 1.

\begin{tabular}{|c|c|c|c|c|}
\hline Grade & Normal & Mild & Moderate & Severe \\
\hline \multirow{2}{*}{ PA $(\%)$} & $>-40$ & $-60 \sim$ & $-80 \sim$ & $-95 \sim$ \\
& & -40 & -60 & -80 \\
\hline
\end{tabular}

Table 1. Classification of drought conditions by precipitation anomaly percentage

3.1.2 Monitoring process: Using the 30 -year data from China Meteorological Data Network from 1986 to 2016 to calculate the average rainfall of each month, and then calculate the PA value of each site in March 2016 according to formula (1), and obtain the PA of the research area after spatial interpolation. Then judge the level.

\subsection{Drought monitoring method based on anomaly vegetation index}

3.2.1 Method principle: The AVI relates the change of NDVI to the "Anomaly" in weather and climate studies, and compares and analyses the relationship between the change of NDVI and short-term changes in climate conditions as a measure of drought monitoring (Pengxin Wang et al., 2003; Pengxin Wang et al., 2007; Lei Gao et al., 2007). The calculation formula is:

$$
A V I=N D V I_{i}-\overline{N D V I}
$$

where $\quad \mathrm{NDVI}_{\mathrm{i}}=$ NDVI value of a certain period in a certain year

$\overline{\mathrm{NDVI}}=$ average value of NDVI in this period for many years

According to the "Code for Remote Sensing Monitoring and Evaluation of Flood and Drought Disasters" (SL 750-2017), the drought classification is shown in Table 2.

\begin{tabular}{|c|c|c|c|c|}
\hline Grade & Normal & Mild & Moderate & Severe \\
\hline \multirow{2}{*}{ AVI } & $-0.2 \sim 0$ & $-0.3 \sim$ & $-0.4 \sim$ & $-0.6 \sim$ \\
& & -0.2 & -0.3 & -0.4 \\
\hline
\end{tabular}

Table 2. Classification of AVI drought conditions 
3.2.2 Monitoring process: Using the NDVI data from 2009 to 2018 in the study area MODIS, layer overlay and band calculation to obtain the average NDVI of ten years, and the band calculation again to obtain the March 2016 AVI value, and the study area division was determined according to the AVI drought classification table.

\subsection{Monitoring method of irrigation area based on surface temperature}

3.3.1 Method principle: Because of different factors such as solar radiation, physical state, and thermal characteristics, the surface temperature and daily variation of different ground objects are significantly different, as shown in Figure 3 . The specific heat capacity of water body is the largest. The temperature of water body at night is higher than that of other ground features, while the temperature of daytime is lower than other ground features, so the daily temperature difference of water body is the smallest. For the bare soil area, the dry bare soil has a large change in daily temperature difference because of its small specific heat capacity. When the bare soil contains water, the temperature change approaches the water body, and the daily difference becomes smaller. For vegetation coverage areas, when vegetation is under drought stress, daytime transpiration is weakened and the calories consumed are reduced. Therefore, the canopy temperature is higher than that of vegetation without drought stress, and the heat dissipation rate at night is faster than that of vegetation without drought stress. As a result, the daily difference becomes larger.

Based on the above, the daily temperature change in an irrigated area is significantly smaller than in an unirrigated area. Therefore, whether an area is irrigated can be determined by determining the daily temperature difference threshold ( $\triangle \mathrm{Ts}$ ). When the regional daily difference is less than $\triangle \mathrm{Ts}$, the area is considered to be irrigated.

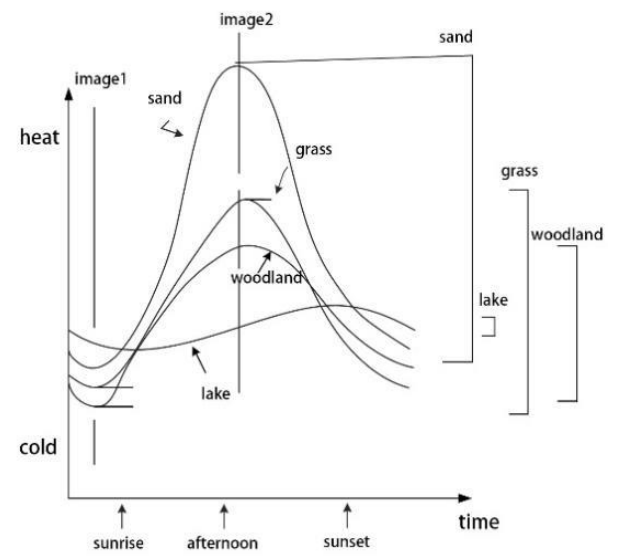

Figure 3. Diurnal variation of surface temperature of typical terrain (Yingshi Zhao et al., 2003)

3.3.2 Monitoring process: When using MODIS surface temperature products to obtain the irrigated area, the daily difference data is first calculated, and $\Delta \mathrm{Ts}$ is determined using 24 sample points collected from field surveys in rain-fed areas. Secondly, the decision tree method is used to eliminate the data affected by rainfall. The data on the day of precipitation and the first day after precipitation are excluded; on the 2nd to 5th days after precipitation, if the first day after precipitation is not irrigated but the irrigation is displayed on the second or subsequent days, it is retained; If the first day after precipitation is irrigated, the next day and the following days show irrigation and the day-to-day temperature difference becomes larger, then it is excluded. In addition, a pixel may be identified multiple times, so the decision tree method is used for a month cycle (starting with the first monitoring of irrigation). If the same pixel has multiple irrigations in a cycle, it is considered a single treatment.

\section{RESULTS}

Using the precipitation data from the site, the percentage of precipitation anomalies at the monthly scale (March 2016) in the study area was calculated. The drought characteristics of the irrigation area at the monthly scale were analysed to assess the severity of the drought. The results are shown in Figure 4. There was severe drought in the south-western part of the study area, and it was moderately dry overall. Among them, the area of severe drought was $254,200 \mathrm{mu}$, accounting for $20.10 \%$ of the total area; the area of moderate drought was $1,010,800 \mathrm{mu}$, accounting for $79.90 \%$ of total area, as shown in Figure 5.

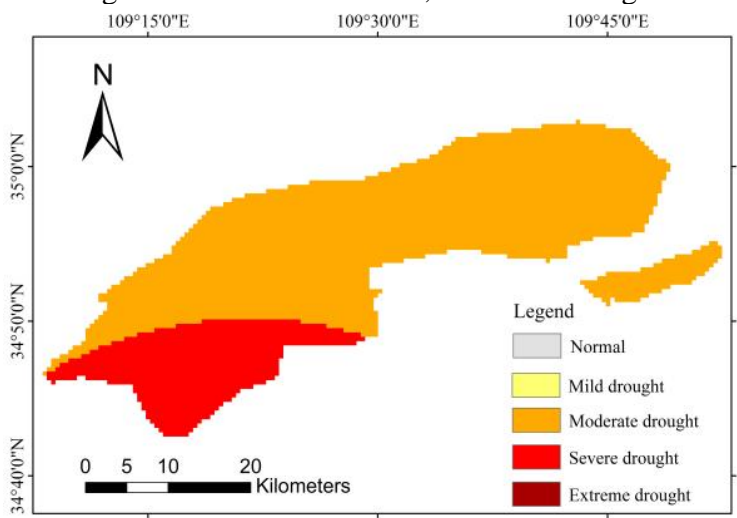

Figure 4. Drought monitoring results based on the percentage of precipitation anomalies in the study in March 2016 in Donglei Irrigation District (Phase II )

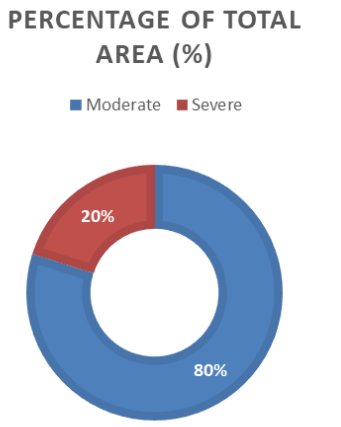

Figure 5. Proportion of dry area of each type based on the percentage of precipitation anomaly in March 2016 in Donglei Irrigation District (Phase II )

Irrigation areas generally have comprehensive irrigation measures, especially in arid-semi-arid areas. The state has invested a lot of funds to build irrigation facilities to ensure that irrigation is carried out during important growth periods of crops and to ensure food security. During the drought period, irrigation districts can fight drought and reduce disasters through irrigation to ensure grain production. Crops have different sensitivities to drought during different growth stages. Even if drought occurs, as long as irrigation is carried out during important growth stages that affect food production, agricultural drought will generally not be caused. 
March is an important season for wheat growth, and irrigation in the irrigation district will not produce a large-scale agricultural drought, which is consistent with the results of drought monitoring based on the anomaly vegetation index (Figure 6): There was no significant drought in the irrigated areas. However, there are rain-fed areas in the irrigated district, which only rely on rainfall for water supply, and the anomalous vegetation index is calculated based on the multi-year average. The rain-fed areas in the study area are always dry, so no drought was detected in the rain-fed area. However, the meteorological drought monitoring based on precipitation anomaly percentage can reflect the drought situation in rain-fed areas relatively accurately.

The irrigation area extracted based on MODIS surface temperature is shown in Figure 7. The south-west and east of the study area were irrigated. The area of the irrigated area was $1021500 \mathrm{mu}$, accounting for $80.75 \%$ of the total area. It can be considered that there was no agricultural drought in the irrigated district. Therefore, the distribution of comprehensive irrigation area in the irrigation district and the remote sensing drought monitoring results based on meteorological data are more accurate, as shown in Figure 8, when drought occurred, the southwest and east of the study area were irrigated, so no significant drought occurred in the southwest and east of the study area, and the drought in the rain-fed area did not ease. Among them, the area without agricultural drought was $1021500 \mathrm{mu}$, accounting for $80.75 \%$ of the total area; the area of moderate drought was $240,400 \mathrm{mu}$, accounting for $19.00 \%$; the area of severe drought was $3100 \mathrm{mu}$, accounting for $0.25 \%$ of the total area. And the statistics are shown in Table 3.

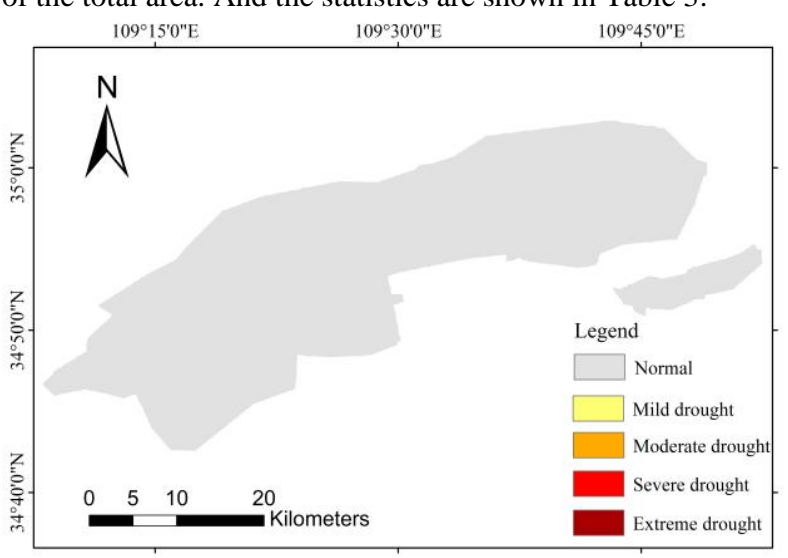

Figure 6. Drought monitoring results based on the anomaly vegetation index in the study in March 2016 in Donglei Irrigation District (Phase II )

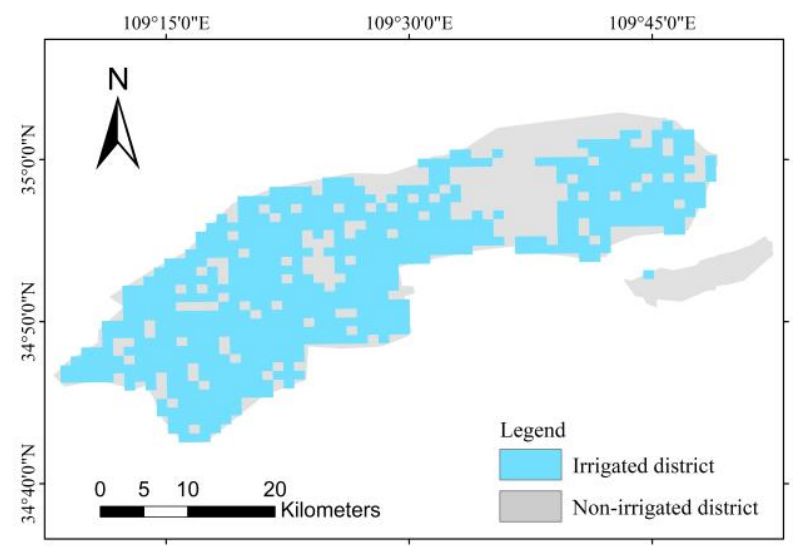

Figure 7. Monitoring results of irrigated area based on surface temperature in the study area in March 2016 in Donglei Irrigation District (Phase II )

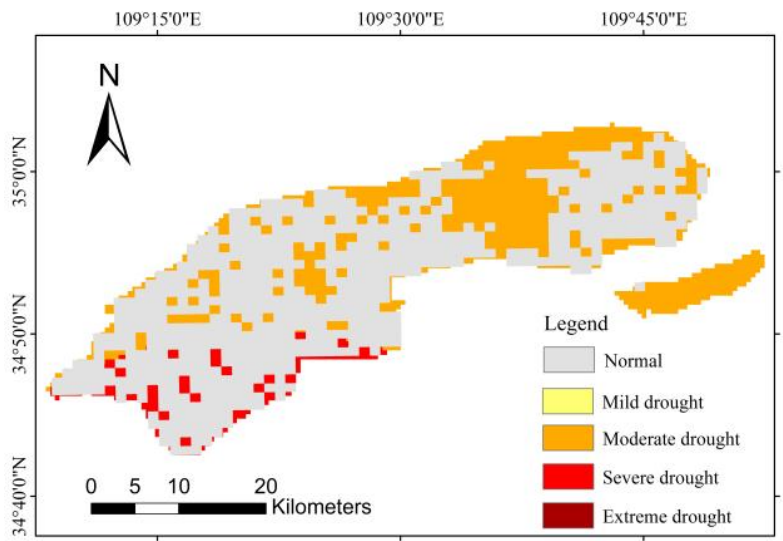

Figure 8. Comprehensive monitoring of drought conditions in March 2016 in Donglei Irrigation District (Phase II)

\begin{tabular}{|c|c|c|}
\hline Drought & Area(mu) & $\begin{array}{c}\text { Percentage of } \\
\text { total area }(\%)\end{array}$ \\
\hline Normal & 1021500 & 80.75 \\
Moderate drought & 240400 & 19.00 \\
Severe drought & 3100 & 0.25 \\
\hline
\end{tabular}

Table 3. Drought monitoring area and percentage of total irrigation area to total area

\section{CONCLUSIONS}

When monitoring drought conditions in the irrigation district, both the drought monitoring method based on meteorological data and the drought monitoring method based on remote sensing index have certain limitations. The single station and its interpolated drought monitoring method based on the percentage of precipitation anomalies measure the degree of meteorological drought based on the precipitation in the study area at a certain time scale, and cannot accurately reflect the degree of agricultural drought in the irrigation district; Crop drought is closely related to soil water content. The amount of soil water content affects crop growth. When crop growth does not get the required water, crop growth is subject to drought stress. The anomalous vegetation index can pass the corresponding multi-year average growth status of the crop. Than the precipitation anomaly more reasonably reflects the degree of agricultural drought, but there are still some problems in monitoring agricultural drought, especially for rain-fed farmland in arid and semi-arid areas, using the anomalous vegetation index cannot truly reflect the degree of agricultural drought.

In the irrigation district, to ensure that irrigation is carried out during the important growth period of the crop, there will not be a large-scale agricultural drought, which can guarantee food production. Therefore, the irrigated area can be used as one of the important indicators to help assess the drought in large irrigation districts. Combined with the drought monitoring indicators to achieve the purpose of accurately reflecting the agricultural drought situation in the study area and improve the precision of agricultural drought monitoring.

In irrigation districts, the role of irrigation measures should be fully emphasized, and dynamic monitoring of irrigation areas 
should be carried out. In irrigation districts, the role of irrigation measures should be fully emphasized, and dynamic monitoring of irrigation areas should be carried out. Combining with the meteorological drought index such as precipitation anomaly percentage and remote sensing monitoring index such as anomalous vegetation index, it is more reasonable to carry out a comprehensive assessment of drought conditions, and the obtained drought monitoring results are more scientific and objective. It can provide a more accurate basis for government and agricultural related departments to carry out water resources planning and formulate drought resistance policies.

\section{ACKNOWLEDGEMENTS}

This work was supported by the National Key R\&D Program of China (2018YFC1508702, 2016YFC0400106-2), by the Natural Science Foundation of China (51609259), and by the Research Program of China Institute of Water Resources and Hydropower Research (JZ0145B472016, JZ0145B862017).

\section{REFERENCES}

Chunsheng Yao, Zengxiang Zhang, Xiao Wang. Inversion of Soil Moisture in Xinjiang Using Temperature Vegetation Drought Index Method (JDI) [J]. Remote Sensing Technology and Application, 2004(06):473-478.//doi.org/ 10.3969/j.issn.1004-0323.2004.06.008

Ezzine H, Bouziane A, Ouazar D. Seasonal comparisons of meteorological and agricultural drought indices in Morocco using open short time-series data[J]. International Journal of Applied Earth Observation and Geoinformation, 2014, 26 : $36-48 . / /$ doi.org/ 10.1016/j.jag.2013.05.005

Gumma, M. K., 2011. Mapping rice areas of south Asia using modis multitemporal data. Journal of Applied Remote Sensing, https://doi.org/10.1117/1.3619838.

Henry A J. The Climatology of the United States//Washington D C: Weather Bureau Bulletin Q, 1906: 51-58.

Huan Liu, Ronggao Liu, Shiyang Liu. Drought Remote Sensing Monitoring Methods and Their Application Development. Journal of Geo-Information Science, 2012// doi.org/ CNKI: SUN: DQXX.0.2012-02-012.

Jie Wei, Zhuguo Ma.Comparison of Palmer Drought Index, Surface Humidity Index and Precipitation Anomaly [J] .Acta Geographica Sinica, 2003(S1):117-124. //doi.org/10.3321/j.issn:0375-5444.2003.z1.014

Kogan F N. Remote sensing of weather impacts on vegetation in non-homogeneous areas [J]. International Journal of Remote Sensing, 1990, 11(8): $1405 \quad$ - 1419. //doi.org/10.1080/01431169008955102

Lei Gao, Zhihao Qin, Liping Lu. Review of Agricultural Drought Monitoring Models Based on Vegetation Index and Surface Temperature Characteristic Space .Remote Sensing for $\begin{array}{llll}\text { Land \& } \quad \text { Resources, } 2007 \quad \text { (03): } & 1-7 .\end{array}$ //doi.org/CNKI:SUN:GTYG.0.2007-03-000

Limin Wang, Jia Liu, Lingbo Yang, Hui Deng, Fugang Yang, Fuhua Ji. Principles, Methods and Applications of Remote Sensing Monitoring of Agricultural Drought .China
Agricultural Information, 2018, 30 (04): 32-47. //doi.org/ 10.12105/j.issn.1672-0423.20180403

McKee T B, Doesken N J, Kleist J. The relationship of drought frequency and duration to time scales. Proceedings of the 8th Conference on Applied Climatology: American Meteorological Society Boston, MA, 1993, 179-183.

Mei Ding, Huixiao Wang, Meihong Ma, Huicai Yang, Ruxin Zhao, Qi Liu. Analysis of Drought in Harbin City Based on Percentage Index of Precipitation Anomaly. Water Saving Irrigation, 2017 (07): 114-118. //doi.org/ 10.3969/j.issn.10074929.2017.07.025

Ming Yan, Lei Zhang. Application of anomalous vegetation index to crop drought monitoring in Jilin Province [J] .Modern Agricultural Science and Technology,2010(11):15-16.//doi.org/ 10.3969/j.issn.1007-5739.2010.11.003

Mlenga Daniel H,Jordaan Andries J,Mandebvu Brian. Integrating Standard Precipitation Index and Normalised Difference Vegetation Index for near-real-time drought monitoring in Eswatini. [J]. Jamba (Potchefstroom, South Africa), 2019, 11(1).//doi.org/ 10.4102/jamba.v11i1.917

Ouzemou, J., El Harti, A., El Moujahid, A., Bouch, N., El Ouazzani, R., Lhissou, R., et al. 2015. Mapping crop based on phenological characteristics using time-series NDVI of operational land imager data in Tadla irrigated perimeter, Morocco. Remote Sensing for Agriculture, Ecosystems, \& Hydrology XVII. International Society for Optics and Photonics. https://doi.org/10.1117/12.2194466.

Palmer W C. Meteorological drought//US Department of Commerce, Weather Bureau Washington, DC, USA, 1965.

Patel N. R. , Anapashsha R. , Kumar S. , et al. Assessing potential of MODIS derived temperature/vegetation condition index (TVDI) to infer soil moisture status. International Journal of Remote Sensing, 2009, 30(1): 23 39. //doi.org/10.1080/01431160802108497

Pengxin Wang, Jianya Gong, Xiaowen Li, Jindi Wang. Drought Monitoring Model Based on Vegetation Index and Land Surface Temperature. Advances in Earth Science, 2003 (04): 527-533. //doi.org/ 10.3321/j.issn:1001-8166.2003.04.008

Pengxin Wang, Wei Sun. Comparative analysis of drought monitoring methods based on vegetation index and surface temperature. Journal of Beijing Normal University (Natural

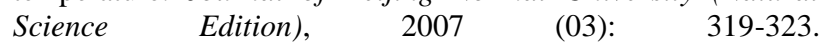
//doi.org/CNKI:SUN:BSDZ.0.2007-03-018

Shuhua Qi, Changyao Wang, Ying Niu. National Drought Monitoring Research Using Temperature and Vegetation Drought Index (TVDI) [J] .Journal of Remote Sensing, 2003(05):420-427+436.//doi.org/ 10.11834/jrs.20030513

Wardlow, B. D., Egbert, S. L., 2008. Large-area crop mapping using time-series MODIS $250 \mathrm{~m}$ NDVI data: An assessment for the U.S. Central Great Plains. Remote Sensing of Environment, 112(3), 1096-1116. https://doi.org/ 10.1016/j.rse.2007.07.019.

Weiying Chen, Qianguang Xiao, Yongwei Sheng. Application of the anomaly vegetation index to monitoring heavy drought in 
1992. Journal of Remote Sensing, 1994, 9(2): 106 - 112. //doi.org/ 10.1007/BF02007173

Wenlong Song, Meng Li, Jingxuan Lu, Yizhu Lu, Yangjun Shi, Haichuan He. Study on Method of Monitoring Irrigation Area Based on GF-1 Satellite Data_-Taking Huanglei Irrigation Area of Donglei Phase II as an Example [J] .Journal of Hydraulic Engineering,2019,50(07):854-863.//doi.org/ 10.13243/j.cnki.slxb.20190258

Xiong, J., Thenkabail, P. S., Gumma, M. K., Teluguntla, P., Poehnelt, J., Congalton, R. G., Yadav, K., Thau, D., 2017. Automated cropland mapping of continental Africa using Google Earth Engine cloud computing. Isprs Journal of Photogrammetry and Remote Sensing, 225-244. https://doi.org/10.1016/j.isprsjprs.2017.01.019.

Yang Song, Shibo Fang, Yaxing Wei. Research Progress on Agricultural Drought Remote Sensing Monitoring Index and Its Applicability. Science \& Technology Review, 2016, 34 (05): 4552. //doi.org/CNKI:SUN:KJDB.0.2016-05-018

Yingshi Zhao. Principles and Methods of Remote Sensing Application Analysis [M]. Science Press, 2003.

Youxin Huang, Xiuguo Liu, Yonglin Shen, Shishi Liu, Fei Sun. Research Progress on Agricultural Drought Remote Sensing Monitoring Indicators and Their Adaptability Evaluation Methods. Transactions of the Chinese Society of Agricultural Engineering, $\quad 2015, \quad 31 \quad$ (16): 186-195. //doi.org/CNKI:SUN:NYGU.0.2015-16-025

Zhongyan Huang, Chu Zhong, Mingda Zhang, Guoqing Xie. Applicability Analysis of Several Drought Indicators in Agricultural Drought Monitoring and Evaluation in Yunnan Drought Year. Chinese Agricultural Meteorology, 2013, 34 (02): 221-228. //doi.org/10.3969/j.issn.1000-6362.2013.02.015 